\title{
Nоті́CIA
}

Sociologias, Porto Alegre, ano 6, no 11, Jan/Jun 2004, p. 352-375

\section{Teses e dissertações defendidas no Programa de Pós-Graduação em Sociologia}

\section{MESTRADO}

Relação das dissertações defendidas em 2003

A afirmação da identidade e a ampliação da cidadania da mulher trabalhadora rural

\section{Autora: Alice Falção Pereira}

Orientador: Prof. Dr. Ivaldo Gehlen

Mês de defesa: Dezembro/2003

O presente trabalho reconstitui a participação das mulheres nas lutas dos trabalhadores rurais e suas mobilizações específicas, no período de 1980 a 1990, com o propósito de buscar seu reconhecimento ante o Poder Público e afirmar seu auto-reconhecimento, ou seja, sua identidade socioprofissional. O contexto do estudo é o da produção agrícola familiar, na qual desencadearam-se, nesse período, lutas pela reforma agrária, por políticas agrícolas e pelos direitos sociais, envolvendo agricultores e agricultoras. A participação das mulheres nessas lutas gerais, favorecida pelo momento político, propiciou a organização das mesmas em torno de sua cidadania. Estas mobilizações e organização levaram à formação do Movimento de Mulheres Trabalhadoras Rurais, no final da década, ampliando seus objetivos iniciais com a inclusão da transformação, através de entrevistas semidiretivas, em amostra selecionada, pela observação participante da autora e pelos documentos produzidos e utilizados no processo de suas lutas. As mulheres afirmaram sua identidade socioprofissional e ampliaram sua cidadania, dentro de um processo de conflitualidades. 
O cotidiano das relações inter-raciais: o processo de criminalização dos atos decorrentes de preconceito de raça e cor no Rio Grande do Sul

Autora: Luciane Soares da Silva

Orientador: Prof. Dr. José Carlos Gomes dos Anjos

Mês de defesa: Agosto/2003

Esta dissertação tem como tema o processo de criminalização de atos tipificados como decorrentes de discriminação racial, a partir da Constituição de 1989, mais especificamente, da lei 7.716, que define a prática discriminatória como crime "inafiançável e imprescritível". Foram analisados 531 casos, registrados nas delegacias do estado do Rio Grande do Sul, entre 1998 e 2001, com o objetivo de compreender a dinâmica das interações raciais no cotidiano e as possibilidades de judicialização desses casos na esfera jurídica. Salienta-se que o cotidiano pesquisado aponta para interações racializadas, enquanto a esfera jurídica tende a des-realização dos casos. Portanto, capitais sociais e escolares, empregados pelos agentes são decisivos na transformação de uma ocorrência policial em um processo judicial.

A democratização do Estado e a participação popular: legitimação do Estado versus autonomia da sociedade civil - uma reflexão sobre o Orçamento Participativo de Viamão/RS

\section{Autor: César André Luiz Beras}

Orientador: Prof. Dr. Enno Dagoberto Liedke Filho

Mês de defesa: Março/2003

O presente estudo busca refletir sobre os processos de democratização do Estado a partir da participação popular. Neste sentido, vamos enfocar 
a experiência do Orçamento Participativo de Viamão 2001/2002. Nosso objetivo, ao contribuir para o processo de construção da democracia enquanto processo de emancipação social é testar as possibilidades democráticas do OP, no sentido de verificar seus limites, enquanto processo que pode expressar relações sociais de dominação. Nesse sentido, partindo de dois pressupostos empíricos: o fato de as experiências do Orçamento Participativo serem, via de regra, induzidas pelo Estado, no caso, o bloco do poder que ora o ocupa; e o fato de os movimentos sociais no Brasil referenciados nos novos movimentos sociais da década de 1970, estarem em refluxo, construímos dois cenários típicos ideais: o da realização da democracia deliberativa e o da realização da dominação burocrático-legal. O cenário típico ideal da democracia deliberativa se referencia na teoria habermasiana e parte de duas referências hipotéticas: a participação autônoma entendida como uma participação auto-organizada, que prepara suas propostas antes das reuniões, com a presença do governo e a participação deliberativa entendida como a participação motivada pela afirmação de espaços públicos nos quais seja possível argumentar e deliberar livremente, controlando o Estado. O cenário típico ideal da dominação burocrático-legal, por sua vez, tem como aporte teórico a teoria weberiana e se referencia hipoteticamente nos conceitos operacionais de participação dependente, que busca conceituar a participação que depende, para seu funcionamento, da estrutura do Estado, logo se estruturando e se organizando a partir e por dentro do processo. O outro conceito é o de participação "interessada" que busca apreender uma participação balizada por um comportamento instrumental, que visa maximizar seus lucros particulares, não preocupado com a construção da democracia. Os resultados alcançados demonstram um cenário híbrido em que algumas condições do cenário de democracia deliberativa, construídas teoricamente, são aceitas, mas, ao mesmo tempo, outras condições do cenário de dominação burocrático legal, também o são. O estudo do OP de Viamão é o estudo de um caso limite que demonstra o conjunto complexo de desafios que engendram a construção de processos democráticos emancipatórios. 
Trajetórias profissionais pós-desligamento de trabalhadores no contexto da reestruturação da indústria de transformação do Município de Caxias do Sul

\section{Autora: Cidriana Teresa Parenza \\ Orientadora: Profa. Dra. Naira Lima Lapis \\ Mês da defesa: Janeiro/2003}

Este estudo tem como objetivo geral a análise da relação entre trajetórias profissionais de trabalhadores desligados da indústria de transformação, delineadas no período posterior ao seu desligamento, e atributos profissionais construídos e acumulados pelo exercício profissional na indústria. Tratase de um estudo exploratório e de uma análise descritiva, realizados com um conjunto composto por 20 trabalhadores desligados, em 1997, dos ramos industriais mecânicos e material de transporte do Município de Caxias do Sul. Pressupunha-se que a introdução de inovações tecnológicas nos trabalhadores, expressas nos processos de contratação, repercutiam, desse modo, nas possibilidades de reinserção profissional. Ao mesmo tempo, dadas as especificidades da reestruturação industrial em curso no Brasil, compreendia-se que as novas exigências poderiam não se estender a todos os postos de trabalho, atenuando as dificuldades de reinserção profissional. Utilizando como abordagem metodológica a análise longitudinal de trajetórias individuais no mercado de trabalho, foram reconstituídas as trajetórias profissionais pós-desligamento dos trabalhadores, bem como identificados os atributos profissionais, acumulados no decorrer de toda a sua vida profissional. As trajetórias pós-desligamento foram tratadas como eventos seqüenciais, sendo que cada um se referia a uma situação de não exercício ou de exercício de atividades laborais. Os atributos profissionais foram definidos como conhecimentos e habilidades de caráter técnico. Com a reconstituição das trajetórias do conjunto de trabalhadores investigados, verificou-se que, em sua maioria, estes retornaram à indústria e aos ramos em que desempenhavam 
suas atividades laborais no período anterior ao desligamento. Quanto à relação entre trajetórias pós-deligamento e atributos profissionais, verificou-se que, mesmo aqueles trabalhadores que não apresentavam atributos referentes ao trabalho com os equipamentos de base microeletrônica ou, ainda, os níveis de escolaridade requeridos pelo mercado de trabalho, retornaram à indústria. O retorno à ocupação profissional daqueles trabalhadores detentores de atributos concernentes ao trabalho com equipamentos de base eletromecânica associa-se, em parte, ao caráter seletivo e heterogêneo da reestruturação industrial. No entanto as informações coletadas revelaram que outros elementos interferiram na reinserção profissional do conjunto de trabalhadores investigados, tais como a existência de vagas no mercado de trabalho e o estabelecimento de vínculos pessoais.

Trajetórias ocupacionais de trabalhadores desligados do setor de telecomunicações

\section{Autor: Paulo Herbert Curtinaz da Silva \\ Orientadora: Profa. Dra. Sônia Maria Guimarães Larangeira Mês de defesa: Setembro/2003}

Esta dissertação reconstitui e analisa as trajetórias ocupacionais dos trabalhadores que aderiram ao Plano de Desligamento Voluntário da Companhia Riograndense de Telecomunicações, no ano de 1996, na modalidade de Pedido de Demissão Voluntária. A amostra é constituída de ocupações típicas do setor de telecomunicações (dez instaladores reparadores de rede e dez engenheiros). O período de reconstituição das trajetórias ocupacionais vai do ano de 1996 até o segundo semestre de 2002. A análise dos dados permite afirmar: a) o direito a indenizações significativas que iam além do previsto em lei, oferecidas por uma empresa estatal, influenciou de maneira positiva as trajetórias ocupacionais; b) a qualificação profissional 
mostrou-se um elemento importante para o destino das trajetórias ocupacionais dentro e fora do setor de telecomunicações, atuando, em determinadas situações, como uma variável capaz de compensar a idade mais elevada da força de trabalho; c) os instaladores apresentaram destinos menos virtuosos que os engenheiros, configurando uma ruptura com a inserção ocupacional estável e ascendente que caracterizou as relações de trabalho durante a vigência do monopólio estatal das telecomunicações; d) redes de contatos profissionais auxiliaram os instaladores a reinserirem-se no mercado de trabalho mais rapidamente no período de expansão das telecomunicações e, e) a família, nos momentos de rupturas dos trabalhadores com o mercado de trabalho, atuou, na maioria dos casos, como suporte social, proporcionando auxílio nos momentos de dificuldade e melhores possibilidades de escolha no mercado de trabalho. Em síntese, a análise dos dados permite afirmar que as trajetórias ocupacionais dos trabalhadores foram fortemente determinadas por fatores de ordem estrutural, sendo a ação dos indivíduos uma resposta às transformações e barreiras que eles passam a encontrar no mercado de trabalho. Dessa forma, os diferentes destinos das trajetórias ocupacionais podem ser interpretados como o reflexo da capacidade ou não de adequação das ações dos indivíduos às transformações estruturais em curso, sofrendo influência de elementos como família e redes de contato, na forma ou na qualidade dessa ação.

Os reguladores do conflito letal: análise dos personagens dos delitos, dos Juízes e das Penas

\section{Autor: Gilson Macedo Antunes}

Orientador: Prof. Dr. José Vicente Tavares dos Santos

Mês da defesa: Fevereiro/2003

Esta dissertação tem por objetivo analisar a importância da atuação dos juízes em relação aos homicídios dolosos ocorridos na capital gaúcha. 
Apresentaremos aqui os procedimentos dos homicídios e julgamentos, bem como aqueles sobre as vítimas dos homicídios no Judiciário. Procuraremos apresentar o perfil das vítimas e dos agressores desses homicídios. Autores com Teresa Sadek, Boaventura de Sousa Santos e Sérgio Adorno serão a base para as conclusões sobre os juízes e os julgamentos ocorridos no Tribunal do Júri.

Participação em saúde na Gerência Distrital 5 de Porto Alegre: Glória, Cruzeiro/Cristal - 1980 a 2000

\section{Autora: Janete Cardoso Réos \\ Orientadora: Profa. Dra. Soraya Maria Vargas Cortes \\ Mês da defesa: Setembro/2003}

Este trabalho apresenta a relação estabelecida entre os atores sociais envolvidos no campo da saúde em Porto Alegre, ao longo das décadas de oitenta e noventa. O estudo focou especificamente a relação entre (a) lideranças do movimento popular e dos usuários do Sistema Único de Saúde (SUS) das regiões Glória, Cruzeiro e Cristal; (b) profissionais e trabalhadores em saúde da área de planejamento da gerência distrital Glória/Cruzeiro/Cristal (GD5) e (c) gestores públicos municipais. Procurou-se verificar quais os fatores que determinaram a ação governamental nas regiões que compõem a GD5, a partir de (a) organização popular e participação; (b) existência de uma policy community reformista regional na área da saúde e (c) sensibilidade e resposta política dos gestores municipais. Para isso, realizou-se um estudo qualitativo, baseado em entrevista e análise documental. A utilização dessa abordagem permitiu identificar a forma peculiar como os atores sociais foram constituindo estratégias de lutas, disputas, conflitos e negociações no campo da saúde, que resultaram em ampliação e melhoria dos bens e serviços disponíveis nas regiões da GD5. 
Qualificação profissional, inserção, reinserção e permanência no mercado de trabalho: os egressos do Programa Integrar

Autora: Margarete Cantu

Orientadora: Profa. Dra. Naira Lima Lapis

Mês de defesa: Fevereiro/2003

Esta dissertação tem como objetivo geral analisar a relação entre a qualificação profissional e a inserção ou permanência dos trabalhadores no mercado de trabalho, tendo como unidade de análise os egressos do Programa Integrar desenvolvido pela CNM/CUT em Porto Alegre e Região Metropolitana. Esse programa diferencia-se das propostas de qualificação profissional desenvolvidas pelos empresários, pelo governo e pelas outras centrais sindicais, pois articula a elevação da escolaridade em nível de ensino fundamental e qualificação técnica, voltando-se para trabalhadores desempregados ou em risco de perder o emprego. Foram entrevistados 21 egressos do PI e um dirigente da instituição executora, com o intuito de investigar qual a contribuição da qualificação profissional, no que diz respeito à elevação da escolaridade, particularmente, e ao aperfeiçoamento da qualificação técnica - operacionalizadas por intermédio do PI - mas também à experiência.

Relações de gênero na agricultura ecológica: um estudo de caso na Região Serrana do Rio Grande do Sul

Autora: Elenice Pastore

Orientador: Prof. Dr. Zander Soares Navarro

Mês de defesa: Fevereiro/2003 
Este trabalho tem como objetivo de investigação os processos de transição ecológica e as relações de gênero, analisando se existe uma simultaneidade de mudanças e no padrão das relações entre as transformações no sistema produtivo e as relações intrafamiliares. Analisa se a implantação e o desenvolvimento de sistemas agrícolas ecológicos produziram alterações e reduções nas desigualdades de gênero. A pesquisa se desenvolveu sob a forma de estudo-de-caso em comunidades rurais dos municípios de Ipê e Antônio Prado, situadas na Região Serrana do Rio Grande do Sul, a qual tem em sua história uma trajetória de implantação da agricultura ecológica há cerca de uma década. A reconfiguração dos padrões de sociabilidade, as relações de trabalho e o papel que mulheres e homens passam a desenvolver a partir dessa nova perspectiva, são discutidos ao longo deste trabalho. A análise do levantamento de dados apresenta resultados significativos, indicando que as modificações no sistema produtivo, as desigualdades de gênero começam a ser superadas e estão em andamento novas configurações que possibilitam relações mais democráticas. A agricultura ecológica é um dos principais espaços de reconstrução de relações e de padrões sociais mais justos e igualitários.

Suicídio: uma análise causal das taxas de mortalidade-suicídio no Rio Grande do Sul

\section{Autora: Rosangela Werlang \\ Orientador: Prof. Dr. Juan Mario Fandiño Mariño \\ Mês de defesa: Fevereiro/2003}

O presente trabalho trata das variações nas taxas de mortalidadesuicídio na totalidade dos municípios do Rio Grande do Sul, Brasil, a partir de uma análise causal do fenômeno. A análise envolveu a construção de 
um modelo teórico, testado através da regressão multivariada. A hipótese central do trabalho, relativa à importância espacial da marginalização de alguns setores do campo na configuração atual da mortalidade-suicídio, confirmou-se. De forma geral, a anomia econômica apresentou-se como mais relevante com relação à variável dependente taxa de mortalidadesuicídio, apresentando um ganho em $\mathrm{R}^{2}$ de $3 \%$, confirmando as relações articuladas no modelo causal.

Na fronteira da emancipação e da colonização através do processo de doação de órgãos

\section{Autor: Mauro Luiz Kaufmann \\ Orientador: Prof. Dr. Renato de Oliveira \\ Mês de defesa: abril/2003}

O estudo apresenta aspectos sociológicos relevantes sobre o comportamento de pessoas que, através da perda de familiares, passaram por situação de decisão de potencial doação de órgãos humanos para transplante. O tema é abordado segundo a teoria habermasiana da ação comunicativa, demonstrando-se que tanto os familiares que optaram pela doação como os que não autorizaram a doação podem ter suas ações compreendidas como tentativas de autonomia dos sujeitos, num mundo caracterizado pela heteronomia. Do ponto de vista empírico, os grupos familiares dividem-se entre o apego a valores tradicionais e a aceitação da modernidade técnica, dicotomia que parece dividir a sociedade brasileira. No entanto, no momento da decisão, é a vontade do morto, expressa em vida, que tende a ser respeitada após a morte. 
Conflitos, trajetórias e engajamentos dos jornalistas na produção de notícias ambientais no Rio Grande do Sul

\section{Autora: Fernanda Rios Petrarca \\ Orientador: Prof. Dr. José Carlos Gomes dos Anjos \\ Mês de defesa: Fevereiro/2003}

Esta dissertação tem como objetivo analisar os conflitos existentes entre jornalistas que produzem matérias ambientais no chamado "jornalismo comercial" e aqueles que se dedicam ao "ecojornalismo", para imposição de uma definição legítima de notícia ambiental. Para dar conta de tal objetivo, consideraram-se as suas relações, por um lado, com as condições estruturais e as correlações de força que pesam sobre os diferentes espaços de produção de notícias e que atuam sobre os jornalistas, contribuindo para a produção de diferentes discursos, bem como para a existência de diferentes definições de notícia ambiental; por outro lado, com as trajetórias, os percursos e os itinerários profissionais que conduzem a determinadas posições tanto dentro do campo jornalístico como a inserção e o engajamento na defesa de princípios que regem os espaços de produção de notícias, como também quanto aos processos de recrutamento profissional, aos princípios de entrada e os recursos sociais necessários para o exercício profissional da temática ambiental nos dois segmentos analisados.

Ação Sindical do Movimento Docente Universitário: 1982-2002

Autor: Alcides José Sanches Vergara

Orientador: Prof. Dr. Antonio David Cattani

Mês de defesa: Julho/2003 
Este trabalho analisa aspectos da ação sindical dos docentes do ensino superior brasileiro no período de 1982 a 2002, após identificar as mudanças gerais nas relações de trabalho, em decorrência da reestruturação no mundo do trabalho e na esfera da educação e no trabalho docente. Na seqüência, são reconstituídas as principais iniciativas dos docentes do ensino superior e analisadas as concepções dos dirigentes sindicais do ANDES - Sindicato Nacional. O contexto das grandes transformações socioeconômicas teve forte impacto nas organizações sindicais dos trabalhadores e, em particular, na categoria docente. A partir dos anos 90, o sindicalismo sofreu com a fragmentação da base militante, com o afastamento de muitos professores e também com o acirramento das disputas internas, enfraquecendo a representação política. Verificou-se que houve uma divisão em grupos assim distribuídos: a) um núcleo de militantes que mantém uma relação orgânica com o movimento e exerce funções de direção; b) um agrupamento igualmente atuante que busca ampliar a pauta sindical e desenvolver uma ação mais institucional; c) um terceiro grupo, maioria do professorado - que atua apenas nas grandes mobilizações como as greves e, finalmente, d) aqueles que não participam mais de nada. Em que pesem as divisões internas do movimento, o sindicato ainda mantém a capacidade de mobilização e de interlocução junto à categoria. O discurso e a vivência das lideranças revelam que, apesar da fragmentação e diferenciação da ação militante durante o período, a renovação do movimento sindical tem acontecido. A atividade militante se mantém numa relação de continuidades e compromisso com a luta sindical, muito embora não nos mesmos patamares alcançados em períodos anteriores. O grande mérito do movimento docente foi o de ter introduzido no espaço acadêmico as demandas sociais e as questões políticas e sindicais, rompendo com a visão elitista e conservadora reprodutora dos interesses das classes dominantes. Este continua sendo o desafio na atual conjuntura. 
Argentinos e brasileiros em Porto Belo: encontros e reencontros

\section{Autora: Laura Mariel Denker}

Orientadora: Profa. Dra. Maria Susana Arrosa Soares

Mês de defesa: Fevereiro/2003

Este estudo aborda o fenômeno do turismo do ponto de vista sociológico, analisando a interação entre os indivíduos que dele participam e o conseqüente intercâmbio sociocultural que dele resulta. O estudo das relações entre os turistas argentinos e os residentes de Porto Belo, em Santa Catarina, durante a temporada de verão, pretende mostrar as transformações desencadeadas pelas relações que se estabelecem entre turistas e residentes na vida desses indivíduos, e o papel cumprido pelo turismo na aproximação e entendimento recíproco entre eles. 


\section{DOUTORADO}

Relação das teses defendidas em 2003

Trabalhadores na reciclagem do lixo: dinâmicas econômicas, socioambientais e políticas na perspectiva de empoderamento

\section{Autora: Clitia Helena Backx Martins \\ Orientadora: Profa. Dra. Anita Brumer \\ Mês de defesa: Dezembro/2003}

Esta pesquisa enfoca as dinâmicas econômicas, socioambientais e políticas de organização, construção da identidade coletiva e empoderamento de trabalhadores em associações de reciclagem, levando-se em conta suas relações com diversos agentes externos. A escolha deste objeto de estudo prende-se a dois aspectos principais:

- à caracterização dessa atividade como uma ocupação em estruturação e processo de reconhecimento, representando uma possibilidade de sustentabilidade e autonomia para setores da população de baixa renda em países em desenvolvimento;

- a uma situação peculiar de relação entre Estado e sociedade, na qual as associações de catadores/recicladores interagem simultaneamente com órgãos dos governos municipais respectivos, do governo estadual e com entidades não-governamentais, como setores da Igreja Católica e ONGs nacionais e internacionais.

Através da análise comparativa das características de três associações de reciclagem na Região Metropolitana de Porto Alegre, verificam-se resultados diferenciados no que diz respeito a processos internos de organização do trabalho e participação nas decisões, bem como em relação às percepções motivacionais e expectativas dos catadores/recicladores quanto à sua ocupação. 
Tendências do controle penal na modernidade periférica: as reformas penais no Brasil e na Argentina na última década

\section{Autor: Rodrigo Ghiringhelli de Azevedo \\ Orientador: Prof. Dr. José Vicente Tavares dos Santos \\ Mês de defesa: Março/2003}

No contexto dos processos de democratização do continente latinoamericano, que ocorreram paralelamente a uma crise do sistema judicial e ao aumento da criminalidade, Brasil e Argentina promoveram significativas alterações legislativas no âmbito da justiça penal, com a criminalização de novas condutas, a criação de mecanismos informais para o processamento de delitos de menor potencial ofensivo e o aumento das penas e a relativização de garantias processuais para determinados delitos. O presente trabalho visa identificar, neste conjunto de movimentos de política criminal, a emergência de um novo modelo de controle penal em países situados no contexto da modernidade periférica. Pretendeu-se realizar um estudo das reformas legislativas em matéria penal, que tiveram lugar no Brasil e na Argentina durante a última década, a fim de compor um panorama dos movimentos de política criminal em relação a períodos anteriores, e apontar os aspectos mais relevantes que indicassem o sentido dos movimentos de reforma em curso. Constatou-se, entre outras, uma tendência à expansão e à desformalização do direito penal, como recurso, na maioria das vezes, meramente simbólico para o enfrentamento de problemas sociais cada vez mais complexos e desafiadores para as estruturas do Estado moderno. 
O Brasil na era do conhecimento. Políticas de ciência e tecnologia e desenvolvimento sustentado

\section{Autora: Maíra Baumgarten Corrêa \\ Orientador: Prof. Dr. Enno Dagoberto Liedke Filho \\ Mês de defesa: Julho/2003}

Este trabalho tem por objetivo analisar as políticas de ciência e tecnologia, na última década do século XX, no Brasil. Buscou-se especificamente verificar potencialidades e limites dessas políticas para a construção de condições de sustentabilidade e para melhorar a posição relativa do País no cenário internacional, caracterizado por economia mundializada e baseada, nos países centrais, em conhecimento intensivo. Visando identificar impactos das formas de gestão e de fomento de ciência e tecnologia sobre o desenvolvimento e a consolidação da base científica e tecnológica brasileira, na década de 1990, investigou-se a relação entre Estado, sociedade e coletividades científicas, expressa em políticas públicas, pelas quais o Estado, com o apoio parcial da coletividade científica, institui a "excelência" como o centro da reorganização do desenvolvimento científico e tecnológico brasileiro, tomando-a como condição essencial para a obtenção dos níveis de competitividade exigidos para a inserção do País na nova ordem econômica mundial. A investigação foi efetuada a partir da análise, por um lado, das macroestruturas sociais representadas pelo Estado (políticas públicas, agências do Estado) e pelo Mercado, estruturas essas que afetam e conectam as microssituações; e, por outro lado, sua relação com os microprocessos que envolvem a ação dos atores presentes no setor de ciência e tecnologia e seu papel na manutenção ou transformação das estruturas sociais. O conceito inclusivo de coletividades científicas, no qual as relações macro e microssociais são contempladas, demonstrou-se profícuo para a investigação das políticas de ciência e tecnologia no Brasil, 
notadamente no que se refere à sua peculiaridade, expressa na inclusão dos cientistas como atores privilegiados na formulação e gestão das mesmas. O estudo conclui que as novas formas de gestão de ciência e tecnologia, no Brasil, que deixam de investir na ampliação horizontal da base de pesquisa e no apoio à emergência de grupos, com capacidade de encontrar soluções para problemas econômicos e sociais, nas diferentes regiões do país (que apresenta dimensões continentais), podem levar a um agravamento das dificuldades para o rompimento do circulo que mantém o país como periférico em relação aos centros dinamizadores de conhecimento e, também, reduzir suas chances de um desenvolvimento sustentável, apesar do discurso e, mesmo, de políticas explícitas em ciência e tecnologia, direcionadas para esse tipo de desenvolvimento.

Extensão universitária no Rio Grande do Sul - concepções e práticas

\section{Autor: Enio Waldir da Silva \\ Orientadora: Profa. Dra. Clarissa Eckert Baeta Neves \\ Mês de defesa: Maio/2003}

Extensão Universitária - Concepções e práticas é o resultado de um trabalho de pesquisa científica centralizada nas dimensões atuais das atividades de extensão desenvolvidas em três universidades gaúchas. Representa um esforço reflexivo na busca de conhecimentos do significado que a extensão vem assumindo junto aos fins da universidade, o papel que ela cumpre diante das perspectivas de transformações das relações universidade e sociedade e das políticas públicas para o ensino superior. A universidade, que sempre se manteve sensível às circunstâncias histórico-sociais, percebe a necessidade de criar formas de procedimentos que possibilitem 
sua presença ativa no meio no qual está inserida, o que implica fazer muito mais do que formar e investigar. O desafio é que as funções de formação e investigação tenham um caráter mais social e que a produção de conhecimentos tenha por base parâmetros com dimensões coletivas, comunicacionais, científico-tecnológicos e, ao mesmo tempo, humanísticos. A extensão universitária, que é uma dimensão nova da universidade, insere-se nesse processo com configurações diferentes, dadas pela realidade institucional. O presente trabalho nos mostrou que, não obstante as diferentes perspectivas e críticas, a extensão, gradativamente, vem esforçando-se para delimitar seu espaço no universo acadêmico da universidade. As concepções sobre sua função são bastante idealistas, e as experiências, frágeis e fragmentadas. Nas diferentes expressões recolhidas, em documentos e falas, porém, percebe-se um esforço em garantir uma identidade para a extensão, que tenha uma eqüidade com o ensino e a pesquisa, com políticas de custeio bem definidas. A nossa tese é que, embora a extensão tivesse ganho uma maior importância neste momento de diálogos sobre a construção de novas esferas públicas, de fortalecimento da sociedade civil e da cidadania, ela não vem tendo uma valorização eqüitativa ao ensino e à pesquisa. A universidade pode construir formas de participação disso, mas não pode fugir de seus padrões acadêmicos, e é isso sua grande dificuldade: sustentar, na extensão, parâmetros de ação que sejam próprios de instituição universitária. Nas universidades gaúchas estudadas aqui: Universidade Federal do Rio Grande do Sul, Universidade de Caxias do Sul e Universidade Católica de Pelotas, não há correspondência entre as concepções e as práticas de extensão, devido não só às suas configurações diferentes de instituições públicas, confessionais e comunitárias, mas também, pela impossibilidade de se enquadrarem à extensão, que é fim e não meio, no ensino, e na pesquisa, ou ao menos, não existe uma maneira de aferir sua contribuição. Ela tem uma função de complemento. 
Exclusão e democracia

\section{Autor: Paulo Roberto Azevedo}

Orientador: Prof. Dr. Raúl Enrique Rojo

Mês de defesa: Fevereiro/2003

Este estudo explora a idéia de que a regularidade civil implica um custo econômico. A investigação sustenta que um significativo setor da sociedade não pode arcar, em seu processo de sobrevivência, com esse custo. A fim de superar esta impossibilidade de participação no mercado formal, tais setores ativariam coletivamente estratégias irregulares de sobrevivência. Por caracterizar-se como um processo de pobreza crônica, esta exclusão motivaria uma produção simbólica que justificaria essas estratégias, bem como desafiaria a legitimidade do poder normatizador público. A partir da metodologia weberiana, este estudo propõe-se a avaliar as conseqüências desse processo para a efetivação da democracia, conforme a concebem a teoria da ação comunicativa de Jürgen Habermas (democracia comunicativa) e a sociologia da ação de Alain Touraine (democracia do sujeito).

As teorias sistêmicas de Vilfredo Pareto, Talcott Parsons e Niklas Luhmann (re)visitadas pela Sociologia do Conhecimento Científico

\section{Autor: Leo Rodrigues Peixoto}

Orientadora: Profa. Dra. Clarissa Eckert Baeta Neves

Mês de defesa: Abril/2003

Esta tese coloca-se no âmbito da Teoria do Conhecimento. Como se trata de conhecimento do conhecimento sociológico, os principais argumentos estão situados nos domínios disciplinares daquilo que Karl 
Mannheim (1982) chamou, na década de 30 do século XX, de Sociologia do Conhecimento e, posteriormente, de Sociologia do Conhecimento Científico. Conduzidos por um referencial analítico, serão (re)visitadas, (re) avaliadas, (re)pensadas três diferentes teorias sistêmicas desenvolvidas pela Sociologia, em momentos distintos, nos quais o conceito de sistema é central, quais sejam: no início do século XX (as duas primeiras décadas), com a teoria sistêmica de Talcott Parsons e, no final do século XX, com a teoria sistêmica de Niklas Luhmann. Nossa investigação centrou-se nas principais obras de caráter sociológico sistêmico dos mencionados autores; são elas respectivamente: "Traité de Sociologie Générale" (1932) (1916-17), "The Social System" (1966, 1968) (1951) e "Soziale Systeme, Grundisse einer Allgeminen Theorie" (1998, 1995) (1984) - nos dois primeiros casos, também foram utilizados os originais em seus respectivos idiomas de publicação; no terceiro caso, foram utilizadas as edições em língua inglesa (1995) e espanhola (1998). Para o estabelecimento de argumentos que sustentam esta tese foi necessário, primeiramente, reconstruir o itinerário teórico realizado ao longo do século XX, que parte da Sociologia do Conhecimento em direção à Sociologia do Conhecimento Científico. Esse itinerário, da forma como foi reconstruído durante a pesquisa, evidencia um fio condutor cujo argumento central é de que o conhecimento, inclusive o conhecimento científico, apresenta condicionantes de natureza social - que se encontravam dispersos em diferentes abordagens teóricas sociológicas. A reconstrução de uma linha argumentativa que parte da Sociologia do Conhecimento (anos 30) em direção à Sociologia do Conhecimento Científico (anos 80), de certa forma inédita nos termos aqui abordados, caracterizará um Referencial Analítico, que será utilizado para (re)visitar criticamente as principais teorias sociológicas que foram desenvolvidas durante o século XX, a partir da adoção de analogias sistêmicas provenientes de outras áreas do conhecimento científico, tais como a Física, a Biologia e a Cibernética. A Sociologia do Conhecimento Científico, com os avanços que foram obtidos durante o século XX desde o aparecimento da Sociologia do Conhecimento, tem reunido argumentos e teoremas que possibili- 
tam a construção de um renovado instrumento para o estudo do próprio conhecimento científico sociológico. Tais argumentos e teoremas, em sua maioria, têm-se contraposto a antigas objeções, normalmente de caráter positivo, meramente analíticas, empregadas tradicionalmente para a análise crítica do uso de analogias, na produção do conhecimento teórico sociológico. É neste sentido que se coloca a necessidade de se (re)conhecer, de (re)avaliar, através da condução de um novo instrumental analítico, as construções analógicas realizadas no âmbito da teoria sociológica.

\section{A nova agência social sindical}

\section{Autora: Elizabeth Kieling Pedroso \\ Orientador: Prof. Dr. Antonio David Cattani \\ Mês de defesa: Maio/2003}

Norteada pelo conceito de agência social (Giddens), a tese é construída identificando a trajetória sindical dos atores sociais e suas possibilidades (os recursos) e limites (os entraves) do exercício da agência social sindical: a capacidade de os dirigentes sindicais interferirem no curso de determinados acontecimentos que afetam a vida dos trabalhadores no final do século XX. Os dirigentes sindicais estudados encontram-se à frente dos sindicatos de trabalhadores urbanos do setor privado das seis maiores cidades do Rio Grande do Sul e seus relatos fornecem elementos para se vislumbrarem as repercussões das mudanças estruturais e conjunturais recentes (reestruturação produtiva e processo de flexibilização das relações de trabalho) sobre o mundo do trabalho e as estratégias adotadas por esses atores sociais para enfrentar, no cotidiano da vida sindical, as principais conseqüências dessas mudanças. A tese demonstra que a crise do poder sindical tradicional não leva as organizações sindicais ao definhamento, nem à extinção do movimento sindical. 
Movimento e organizações sindicais encontram novas formas de enfrentar os problemas que fragilizam os trabalhadores e os sindicatos no período de 1989-2001, e articulam, através dos seus atores sociais centrais - os dirigentes sindicais - duplo procedimento: ocupam novos espaços, ao lado dos espaços tradicionais de atuação sindical, e alternam ações e relações sindicais conflitivas e dialogais. Desta combinação resulta a possibilidade de os dirigentes sindicais preservarem, mesmo que reduzida, a capacidade de defender os interesses dos trabalhadores nas questões específicas das categorias profissionais representadas pelos sindicatos, além de expandir a interferência sindical para novas temáticas - as políticas públicas - participando de novos espaços de âmbito municipal: as comissões e conselhos tri ou multipartites, especialmente as comissões municipais de emprego - as CMEs. Novos espaços de atuação sindical, somados aos tradicionais, e novas relações sociais, mais dialogais, ampliam a visibilidade dos dirigentes sindicais, permitem parcerias inusitadas e os desafiam a desenvolver estratégias que os capacitem a interferir sobre o rumo de certos acontecimentos que afetam a vida dos trabalhadores que representam e de um conjunto maior de pessoas - sua comunidade - delineando um poder de tipo novo.

A reinvenção social do natural: natureza e agricultura no mundo
contemporâneo

Autor: Luciano Félix Florit

Orientador: Prof. Dr. Zander Soares de Navarro

Como explicar o fato de estarmos em um mundo que, ao mesmo tempo em que desafia todos os limites na manipulação da natureza, valoriza as coisas "naturais" na mesma proporção? Qual é a "natureza" recorrentemente invocada no fenômeno de "volta ao natural" das últimas décadas? A 
partir da constatação deste paradoxo, neste trabalho tenta-se fazer uma análise sociológica das especificidades da construção social da idéia de natureza no mundo contemporâneo. A tese sustentada é que a revalorização do natural acontece pela busca de um "refúgio" de confiança perante as incertezas criadas pela proliferação e exarcebação dos riscos. Não obstante isso, o que se entende por natureza nessa revalorização obedece a definições sociais, contendo, paradoxalmente, as "arbitrariedades" próprias da atividade humana das quais tal revalorização da natureza tenta livrar-se. O trabalho apóiase numa análise da produção de alimentos "naturais" pelos movimentos de agriculturas alternativas, críticas dos métodos convencionais da agricultura moderna e portadores de visões diferenciadas de natureza. Do ponto de vista empírico, realiza-se um estudo comparativo dos campos sociais da agricultura "ecológica" e "orgânica" no Rio Grande do Sul e na Argentina, verificando como diferentes condicionantes sociais conduzem a construções diferenciadas do que é considerado "natural".

A sustentabilidade da agricultura familiar no Vale Gurguéia-PI: construção de identidade socioprofissionais

\section{Autor: Ferdinand Cavalcante Pereira \\ Orientador: Prof. Dr. Ivaldo Gehlen \\ Mês de defesa: Dezembro/2003}

Este estudo analisa o desenvolvimento sustentável dos agricultores familiares do Vale do Gurguéia no Estado do Piauí, ameaçados pela expansão da agricultura empresarial no cerrado piauiense. Neste contexto de modernização agropecuária, pela ocupação capitalista - reconcentração de terra e avanço tecnológico - e pela (re)colonização da região, os tradicionais 
produtores familiares enfrentam os impactos e os riscos decorrentes dessa dinâmica de transformações socioeconômicas e institucionais, a partir da construção de identidades socioprofissionais no desenvolvimento de formas organizativas sustentáveis enquanto estratégias alternativas de sobrevivência e de reprodução social. Para tanto, esses agricultores desenvolvem relações socioculturais que se orientam tanto pela recriação de novos contextos interacionais e institucionais de sociabilidade quanto pela especialização de produtos e profissionalização. Nesse sentido, associações e cooperativas emergem como apoio à produção e à conquista de cidadania, espaço político de luta e inclusão social. A sustentabilidade da agricultura familiar é fundamental para o desenvolvimento rural dessa região, porque a sua inserção econômica e social na produção capitalista depende de políticas públicas agrícolas e agrárias conseqüentes. A conclusão do estudo mostra que a forma social de produção familiar, na região, constitui o setor com maior potencial inclusivo dos seus diferentes segmentos, ressignificados segundo os valores culturais locais no uso social da terra e na organização social, para além da reprodução mercantil simples. Enfim, as relações sociais com a terra, o trabalho e o mercado confirmam a existência de novas dinâmicas características da produção familiar em curso na região, quanto à apropriação e ao uso dos recursos disponíveis, instituindo novos e/ou recriando estratégias produtivas e padrões de interação social. 